\title{
EDITORIAL
}

\section{EXPLORING THE POTENTIAL OF NURSES IN THE DELIVERY OF CARE FOR PEOPLE LIVING WITH CHRONIC CONDITIONS}

\author{
Clare Harvey
}

Central Queensland University, Australia

People living with one or more chronic conditions is becoming an everyday occurrence. According to a recent report by the World Health Organization (WHO, 2013), 65\% of all global deaths are attributable to chronic illness, with nearly $40 \%$ of those deaths being in people between the ages of 30 and 70 years old. Concomitantly, the cost of caring for people living with chronic conditions has placed an ever-increasing burden on health care budgets. This is because long term care requires the ongoing support of multiple services. The challenge for health services is to provide the optimum care possible for the least cost. To do this, one must understand that care is no longer just disease focused. Many health services lack the capacity to deal with such complex patients, with fragmentation of care commonplace, resulting in increased admissions and reduced capacity for patients to manage their condition, or have input into their care (Sheridan et al., 2015). The objective is to find new models of care that support an integrated approach to care that is communitybased and addresses the whole-person needs (Boehmer et al., 2018).

There is considerable research identifying the role of nurses as co-ordinators of care in the single chronic condition space, such as cancer care, cardiac care etc. Little identifies this role in the multimorbid space where a person's care is complex as a result of multiple simultaneous chronic conditions. Whilst the rhetoric of person-centred care is evident in health care policies, the key to its success is the care coordinator who works with the patient, the family, community and multidisciplinary health care team (Parker \& Fuller, 2016). Recently in Queensland (Australia) where I am currently working, the state government implemented the role of nurse navigator. Key role principles are a) co-ordinating patient centred care within a multidisciplinary team; b) creating partnerships in care; c) improving patient outcomes and d) facilitating systems improvement. We are now evaluating that role, using measures of service provision, professional capability and capacity, patient self-reported wellbeing and economic effectiveness (Harvey et al., 2019). Results are clearly indicating success in all four role principles with person-centred care clearly shining through.

For the first time in history, nursing and midwifery is being acknowledged for its global contribution to health care, by making 2020 the International Year of the Nurse and Midwife. Both the WHO and the International Council of Nurses have acknowledged the vital role we play in providing health care. As nurses and midwives, this is our time to shine. We are a workforce that spans disease and wellness models by which we can effectively reduce fragmentation of care whilst providing support for improved health literacy and hospital avoidance. Let's show the world that we can make a difference to people living with chronic conditions. We can lead the field in demonstrating effective care coordination.

Assoc. Prof. Clare Harvey RN, BA(Cur), MA, PhD e-mail: c.l.harvey@cqu.edu.au

\section{References}

Boehmer, K. R., Abu Dabrh, A. M., Gionfriddo, M. R., Erwin, P., \& Montori, V. M. (2018). Does the chronic care model meet the emerging needs of people living with multimorbidity? A systematic review and thematic synthesis. PLoS One, 13(2):e0190852. https://doi.org/10.1371/journal.pone.0190852

Harvey, C., Palmer, J., Hegney, D., Willis, E., Baldwin, A., Rees, C., Heritage B., Thompson, S., Forrest, R., O’Donnell, C., Marshall, R., Mclellan, S., Sibley, J., Judd, J., Ferguson, B., Bamford-Wade, A., \& Brain, D. (2019). The evaluation of nurse navigators in chronic and complex care. Journal of Advanced Nursing, 75(8):1792-1804. https://doi.org/10.1111/jan.14041

Parker, S., \& Fuller, J. (2016). Are nurses well placed as care co-ordinators in primary care and what is needed to develop their role: a rapid review? Health and Social Care in the Community, 24(2):113-122. http://doi.wiley.com/10.1111/hsc. 12194

Sheridan, N. F., Kenealy, T. W., Kidd, J. D., Schmidt-Busby, J. I. G., Hand, J. E., Raphael, D. L., McKillop, A. M., \& Rea, H. H. (2015). Patients' engagement in primary care: powerlessness and compounding jeopardy. A qualitative study. Health Expectations: an International Journal of 
Public Participation in Health Care and Health Policy, 18(1):32-43. https://doi.org/10.1111/hex.12006
WHO. (2013). Global action plan for the prevention and control of noncommunicable diseases 2013-2020. WHO Press. 